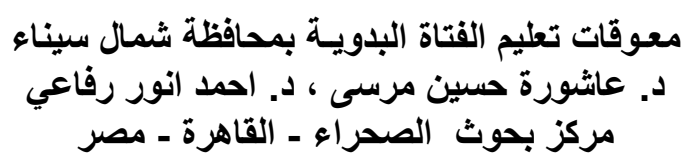

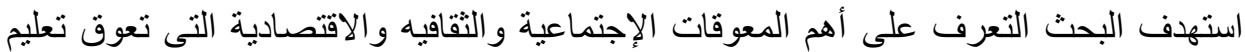

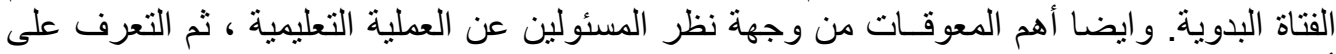

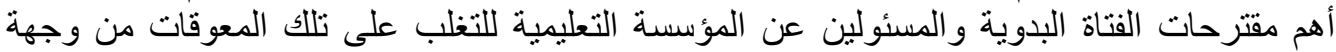

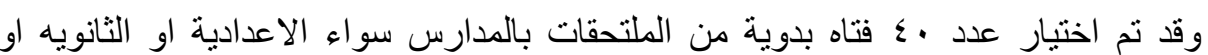
نظر هم.

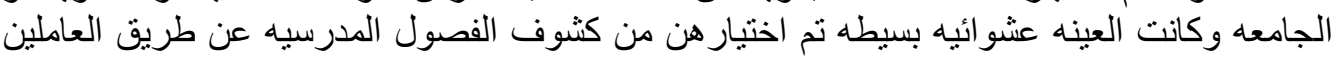

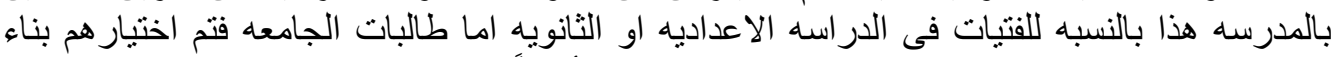

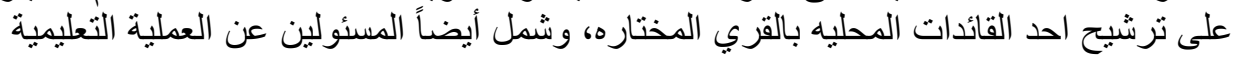

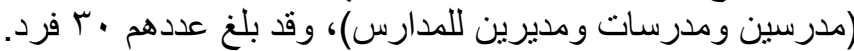

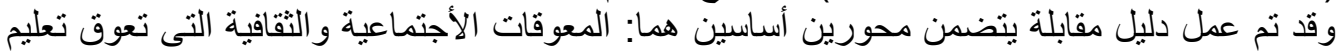

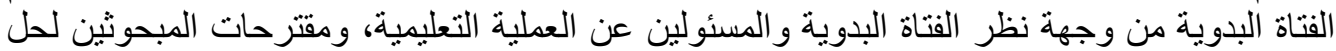

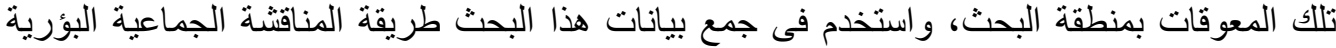

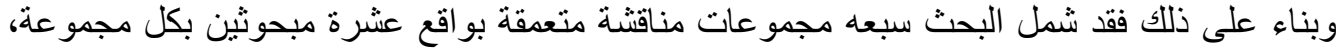

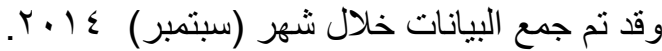
وكانت أهم نتائج البحث مايلي:

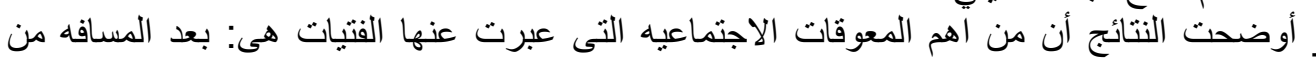

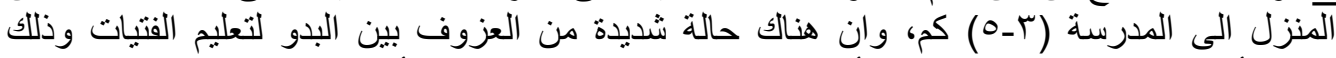

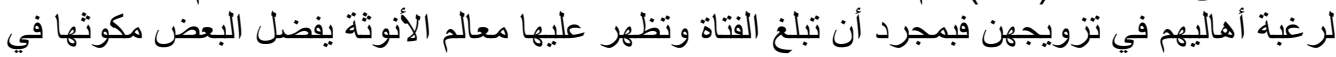

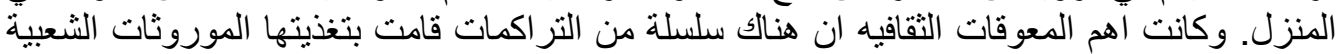

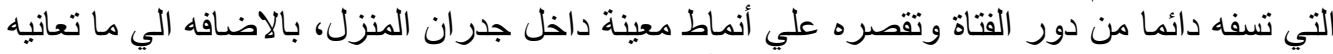

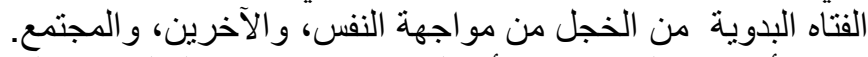

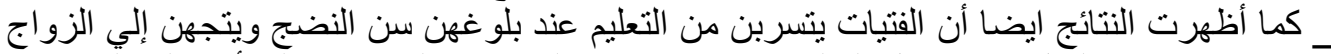

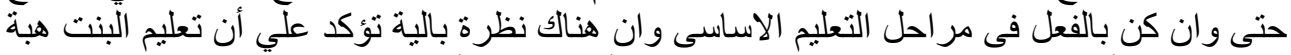

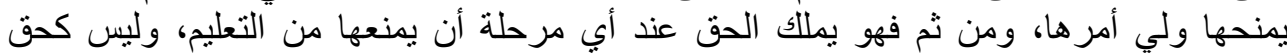

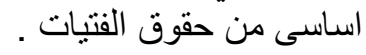

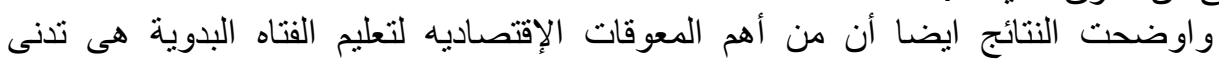

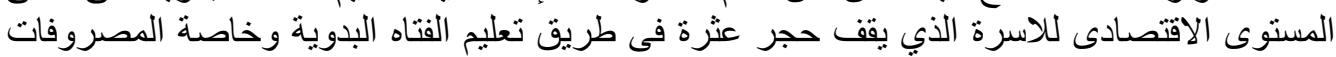

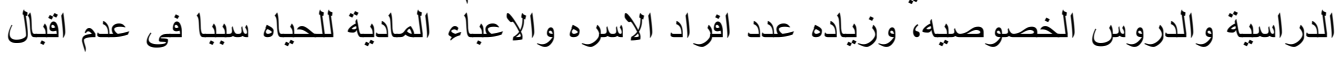
الاسره على تعليم الفتاه.

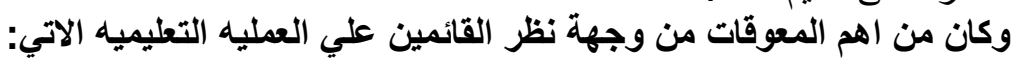

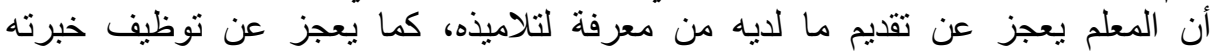

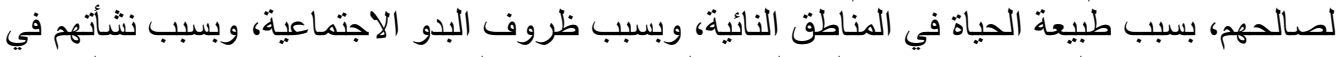

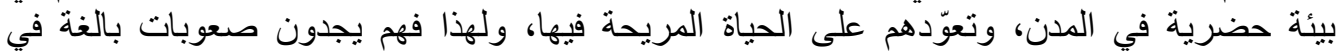

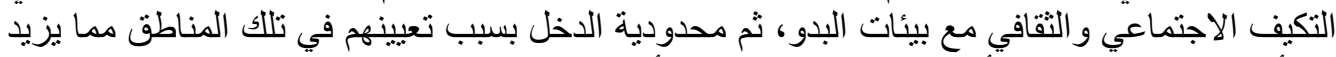

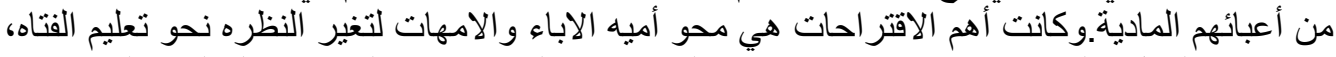

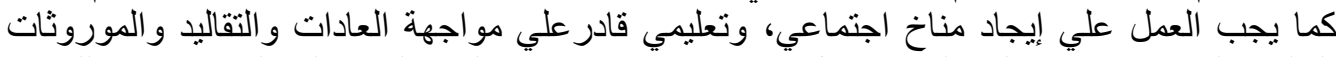

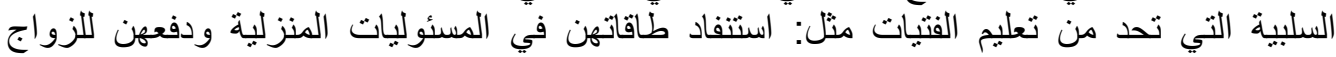

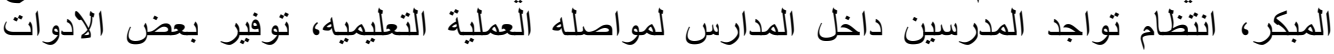

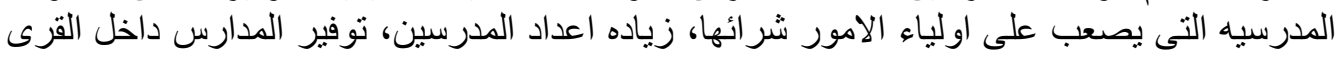

Fayoum J. Agric. Res. \& Dev., Vol. 27, No.2, July, 2014 
$r \Lambda$

حتى تتمكن الفتاه من استكمال تعليمها مثل المدارس الثانويه والثانوية الفنيه محاربه ظاهرة تعدد

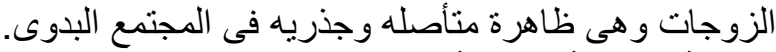
مقدمسة ومشكلة الاراسة:

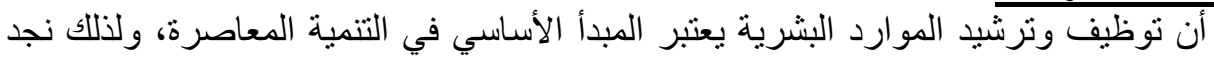

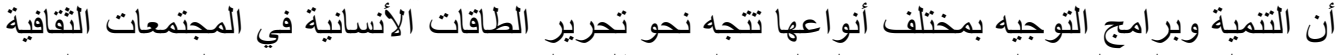

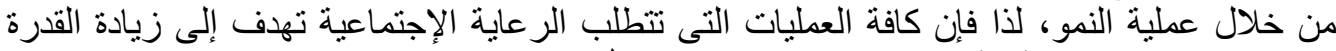

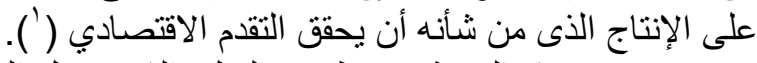

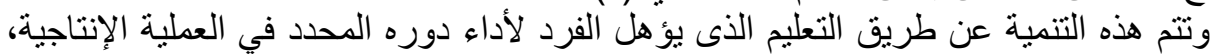

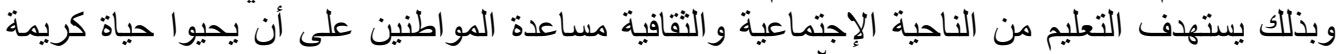

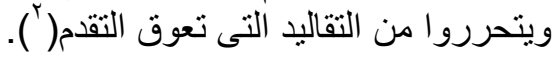

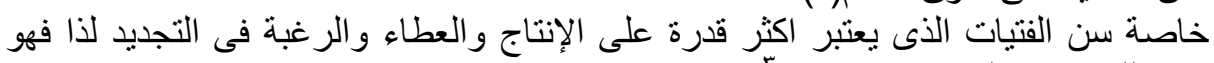

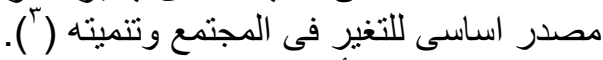

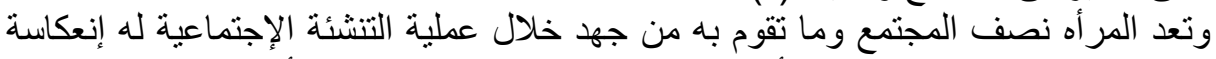

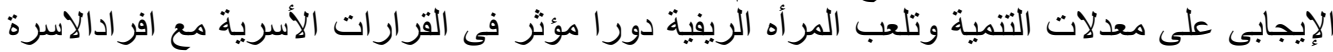

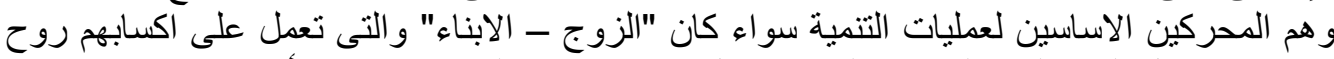

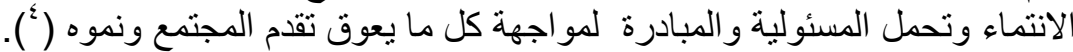

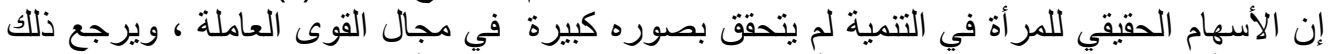

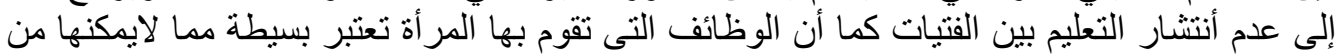

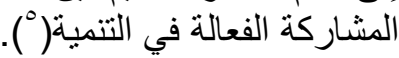

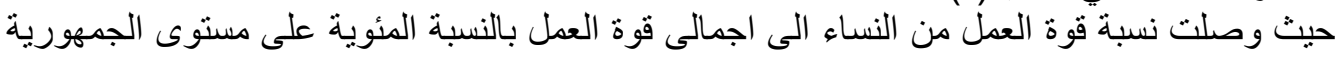

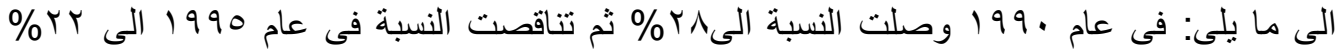

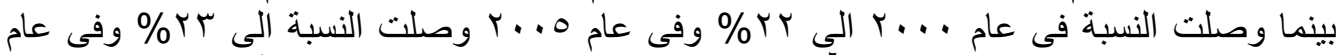

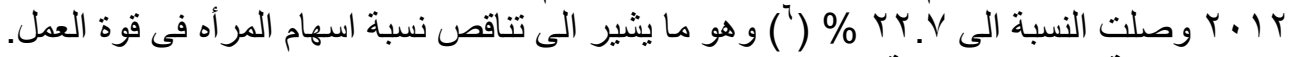
وتتحقق تنمية الموارد البشرية بوسيلتين رئيسيتين:

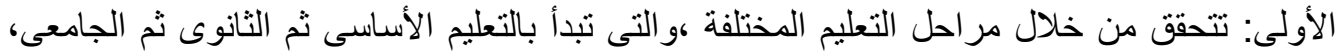

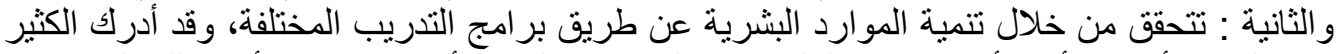

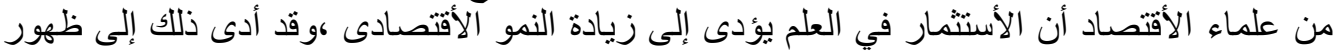

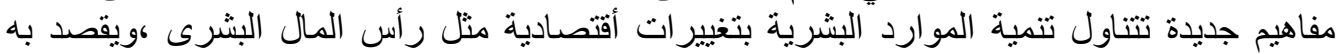

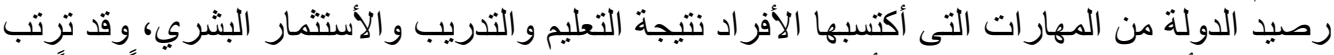

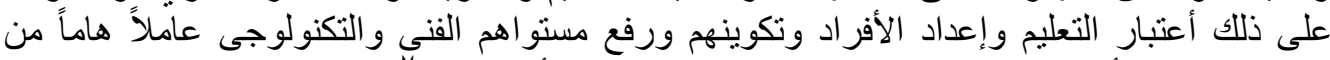

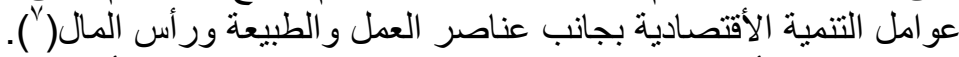

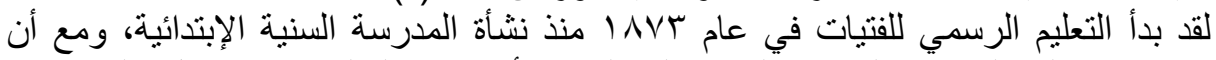

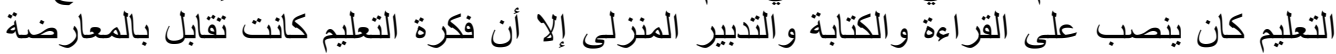

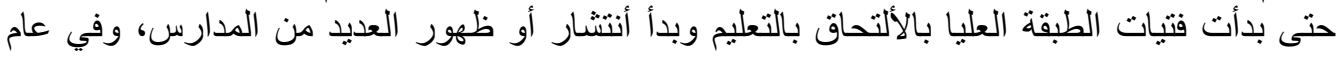

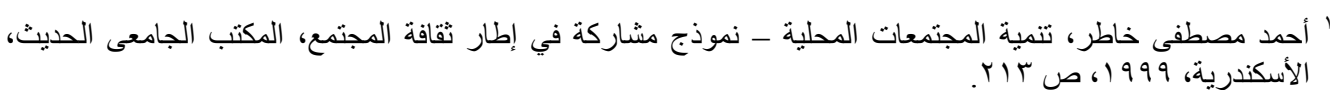

${ }^{2}$ Ministry of education "Education in Egypt" national center for education research center, 1980.

${ }^{3}$ F.M.loewen Bery : fundamentals of social intervention ,new yourk, Guild fed ,1983,p5.

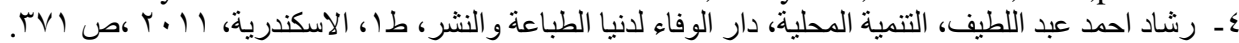

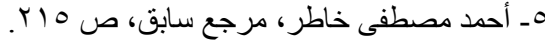

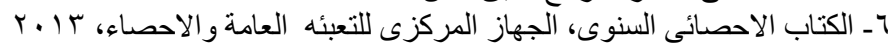

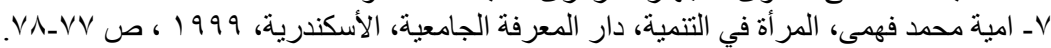

Fayoum J. Agric. Res. \& Dev., Vol. 27, No.2, July, 2014 
rq

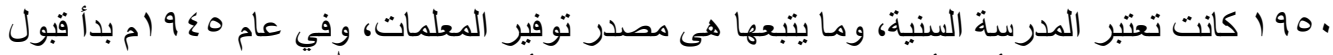

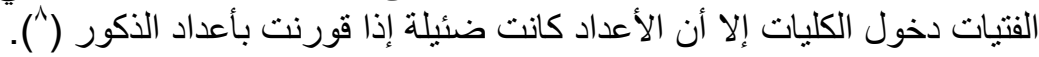

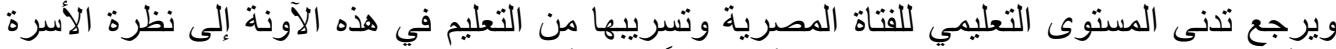
و الأم بصفة خاصة لدور الفتاة حيث يرونه أكثر نفعاً لها ولأسرتها في المنزل فئه فئه كطالبة بالتعليم... وبرجع ذللك إلى عدة عو امل تتمثل في:

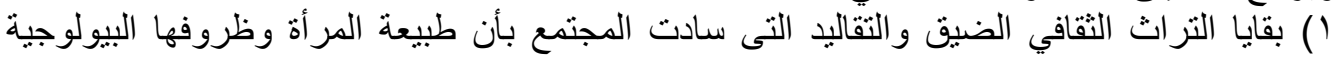

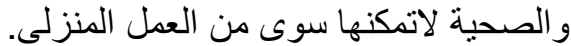
ب) تر اث الأمية الثقيل الذى ورثته المر أة بصفة خاصنة من حصاد مرحلة الأقطاع حيث وصلت نسبة الأمية عام 9 ام ام إلى نسبتها إلى و

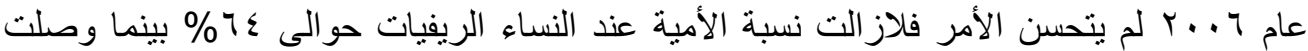

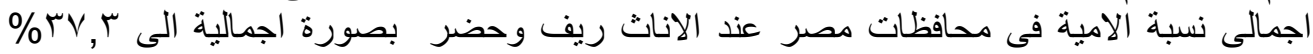

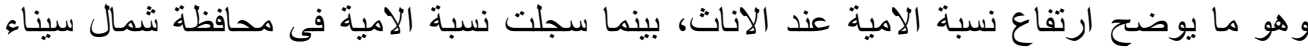

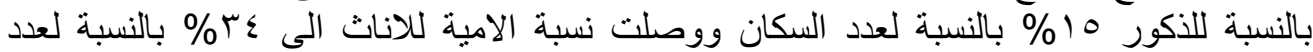

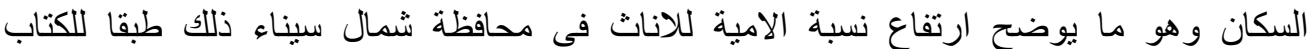

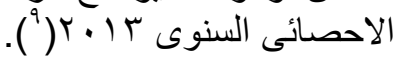

ب) شمولية وثقل العبء العملي لدور المرأة البدوية، فنجد أن دور ها لا يقتصر على مجالات الإقتصاد

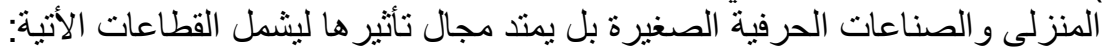

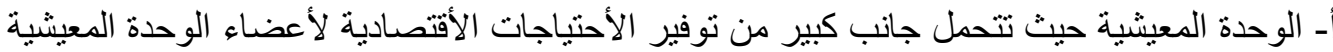

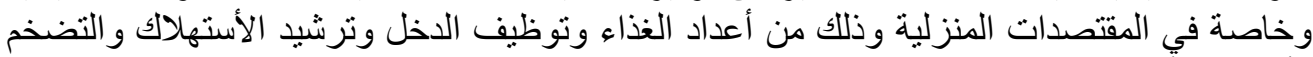

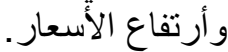

ب- وللمر أث البدوية دور الاسعار هام في الرعى و الأنتاج الحيوانى مثل تربية الأغنام و الماعز و الثروة الداجنة.

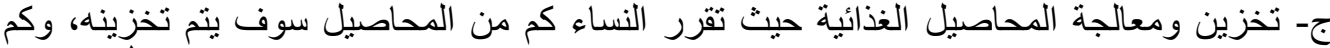

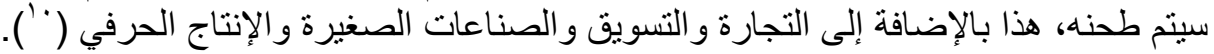

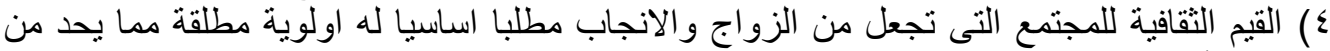

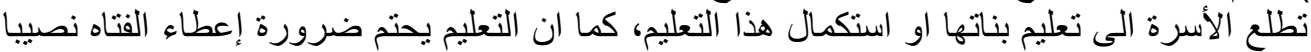

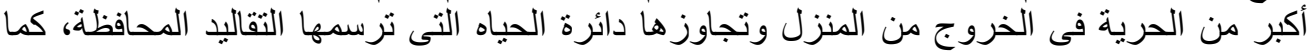

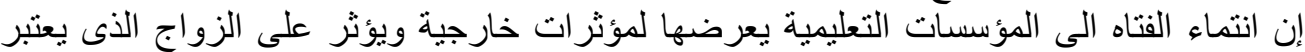

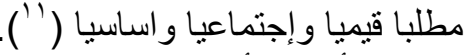
أن المر أة التى تشكل نصف أنَ المجتمع تعتبر عاملاً هاماً من عو امل أحداث التتمية إلا أن هنالك ضرورة متزايدة بالنسبة للنساء للحصول على عمل على مريح.

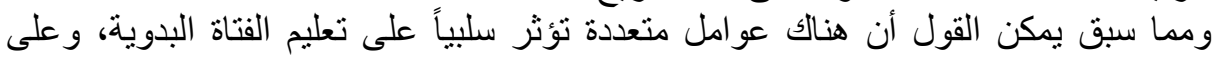

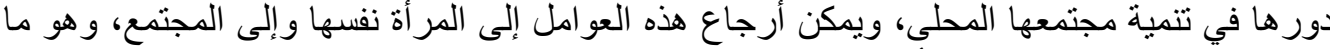

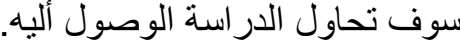
أهـاف الدراسة:

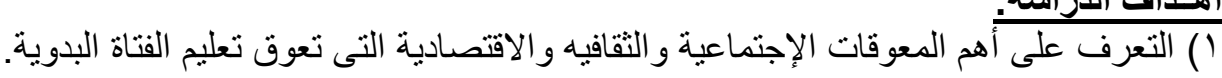
ب) التعرف على أهم المعوقـات من وجهة نظر المسئولين عن العملية التعليمية التى تعوق تعليم الفتاة

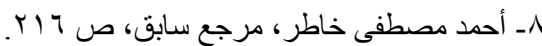

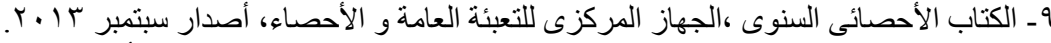

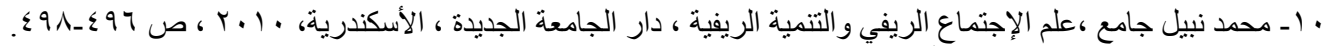

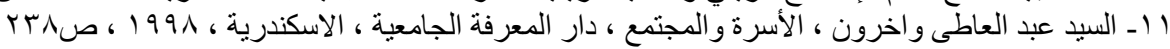

Fayoum J. Agric. Res. \& Dev., Vol. 27, No.2, July, 2014 
$\varepsilon$.

r) التعرف على أهم مقترحات الفتاة البدوية و المسئولين عن المؤسسة التعليمية للتغلب على تلك المعوقات

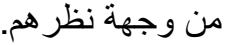

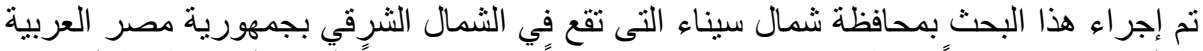

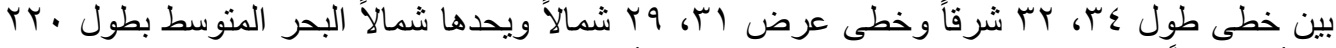

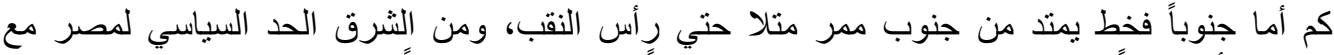

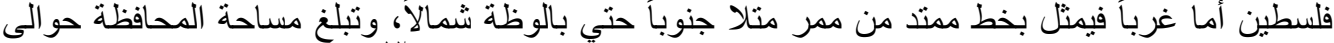

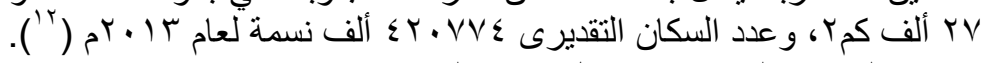

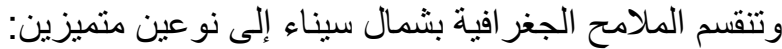

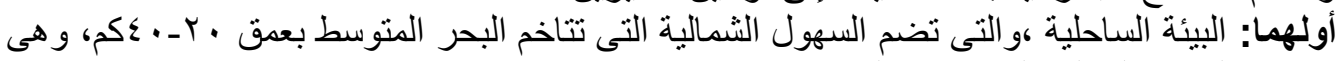
مغطاه بالكثبان الرملية المتموجة و المنبسة المبنة.

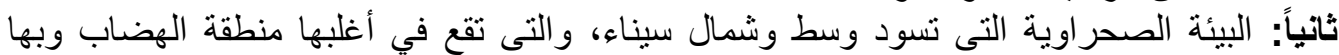

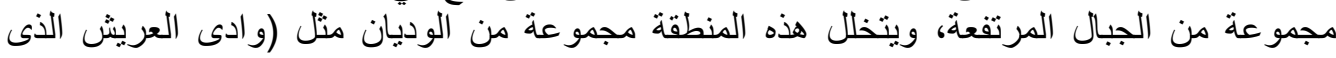
يخترق المحافظة من الثمال إلى الجنوب).

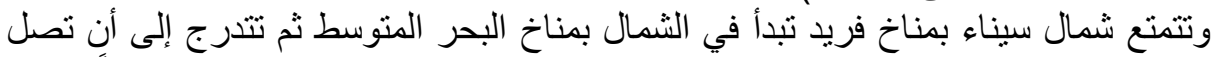

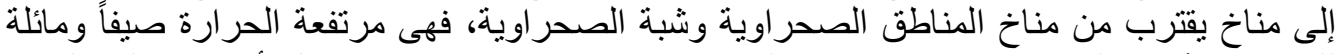

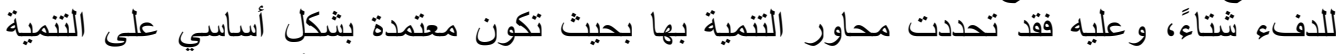

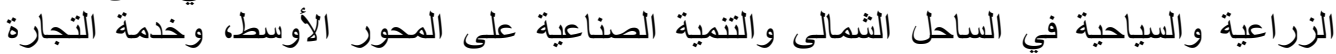

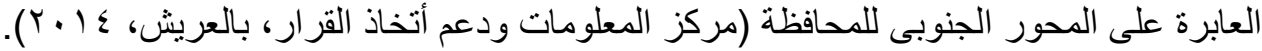

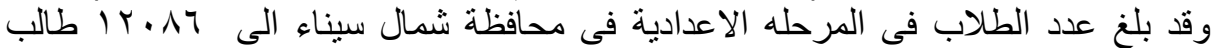

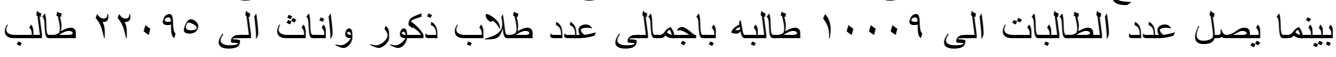

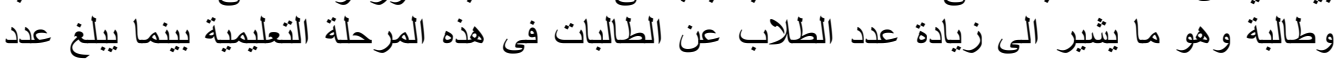

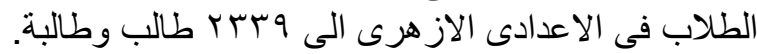

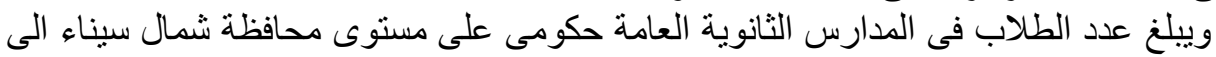

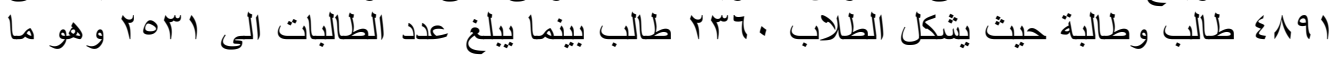

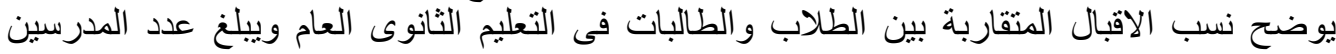

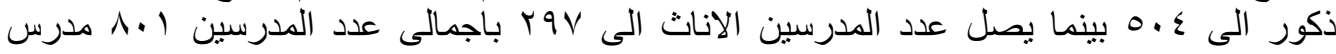

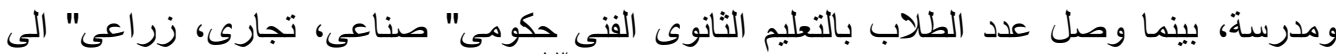

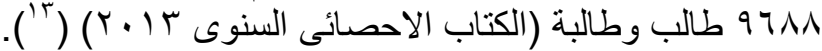

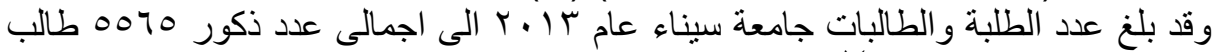

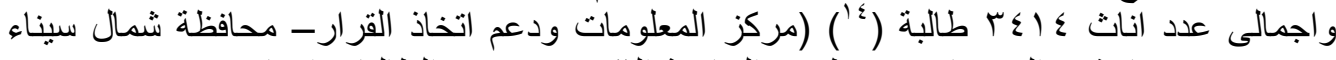

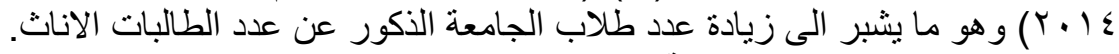

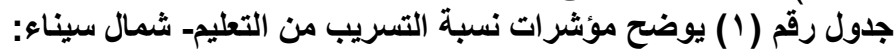

\begin{tabular}{|c|c|c|c|c|c|}
\hline$\%$ & التحق و تسرب & $\%$ & لم يلتحق بالتعليم & \multicolumn{2}{|c|}{ 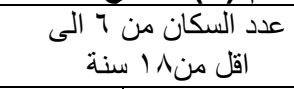 } \\
\hline $1 . \Gamma \varepsilon$ & 770 & r.vo & 1101 & $\sum 9094$ & ذكور \\
\hline T.IT & $9 \leqslant 7$ & $V . I Y$ & rIVT & $\leqslant \leqslant 091$ & اناث \\
\hline 1.81 & 1711 & $0 . \pi 1$ & 0.41 & $9 \varepsilon \backslash \wedge \varepsilon$ & جمله \\
\hline
\end{tabular}

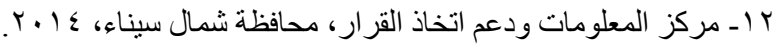

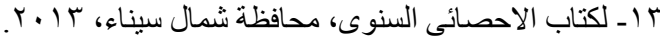

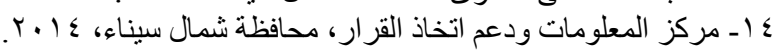

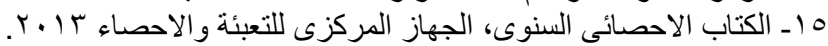

Fayoum J. Agric. Res. \& Dev., Vol. 27, No.2, July, 2014 
\&1

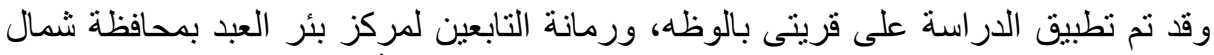

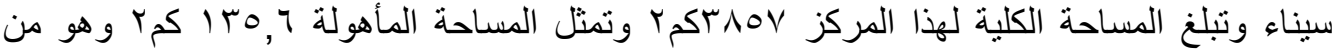

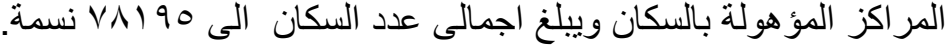

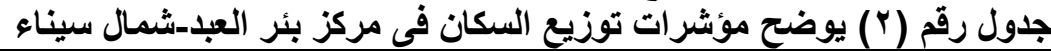

\begin{tabular}{|c|c|c|c|c|c|c|}
\hline \multirow{2}{*}{ اجمالى } & \multicolumn{3}{|c|}{ سكان ريف } & \multicolumn{3}{|c|}{ سكان حضر } \\
\hline & اجمالى & اناث & ذكور & اجمالى & اناث & ذكور \\
\hline$V \wedge 190$ & 7.749 & $\mu \ldots \varepsilon$ & $\mu_{.7 \pi 0}$ & 18007 & NOY & Q.rY \\
\hline
\end{tabular}

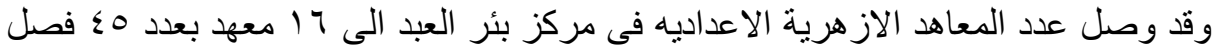

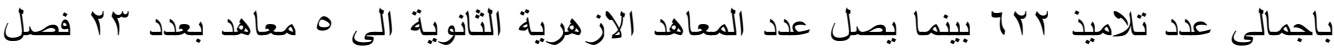

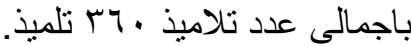

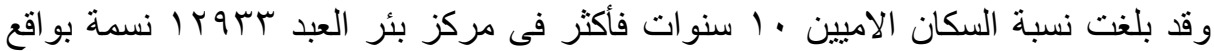

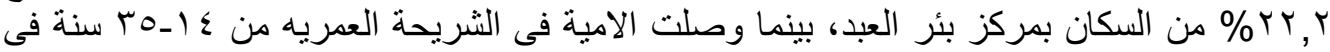

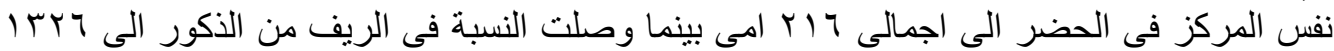

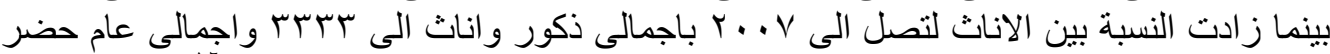

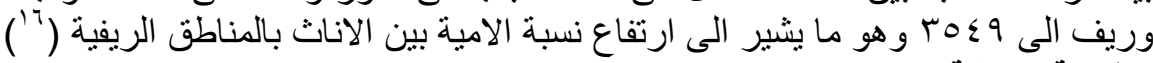

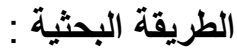

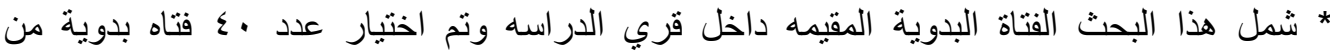

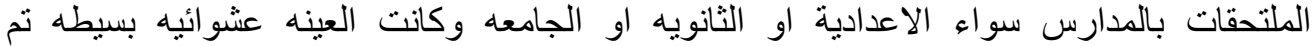

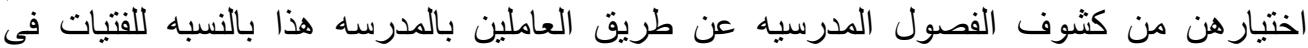

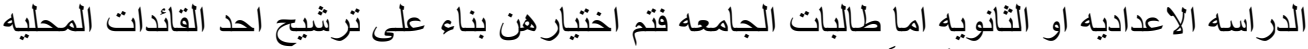

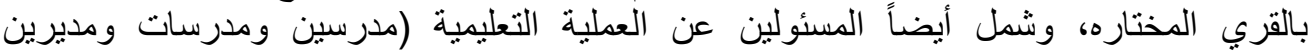

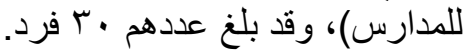

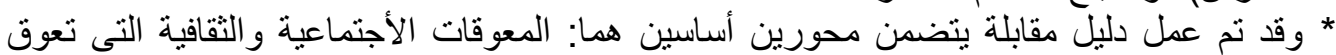

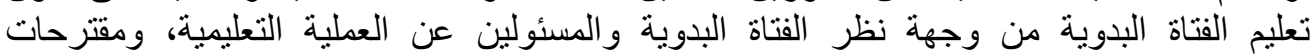

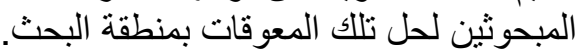

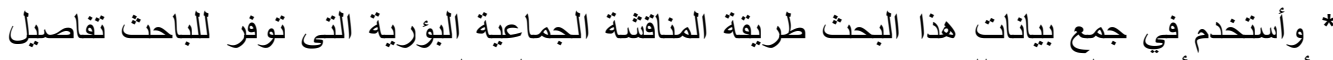

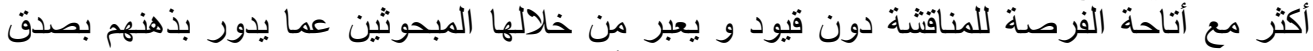

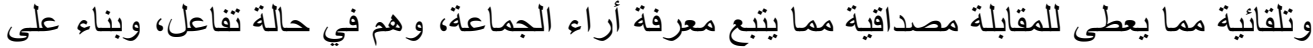

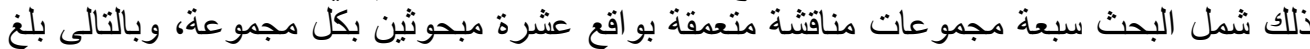

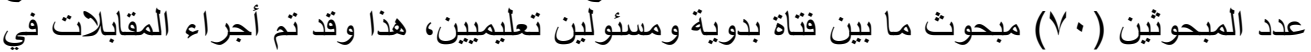

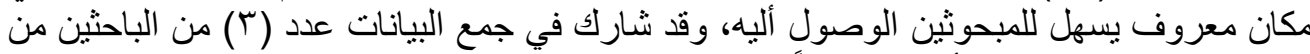

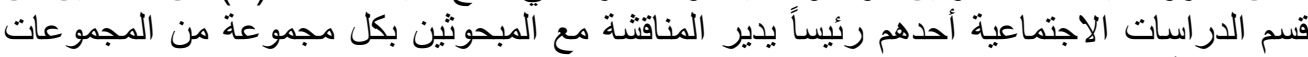

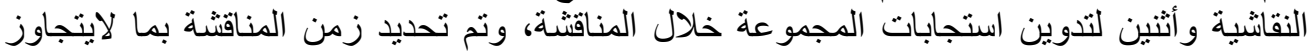

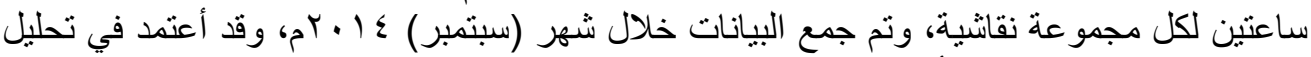

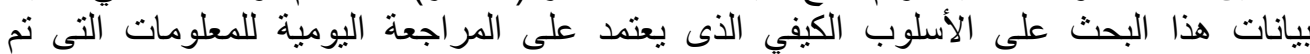

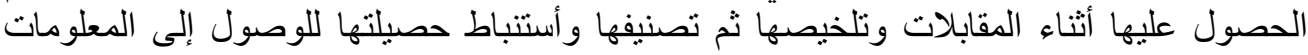

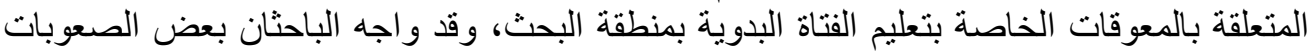
فىى تجميع البيانات الاحصائية نظر اللظروف اللئية الأمنية التى تمر بها المنطقة فى هذه الآونة.

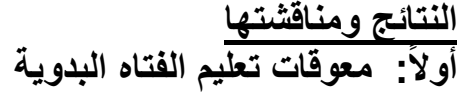

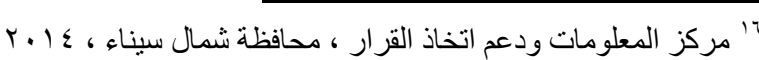

Fayoum J. Agric. Res. \& Dev., Vol. 27, No.2, July, 2014 
أوضحت نتائج الحلقات النقاشية مع المبحوثات من الفتيات عن وجود العديد من الأسباب التى

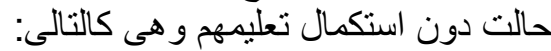

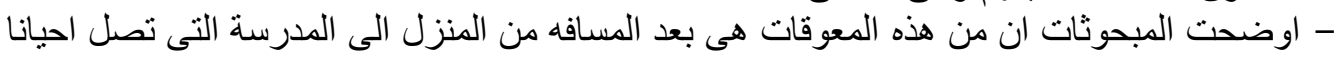

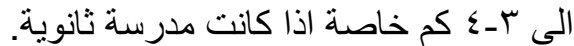

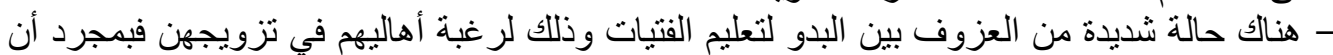

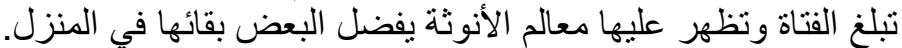

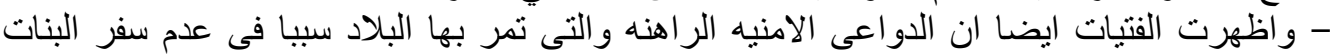

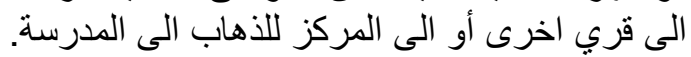

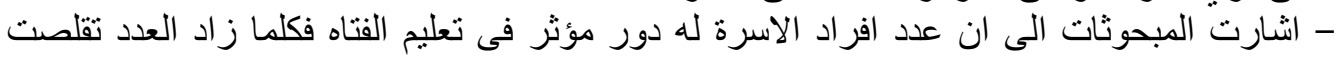

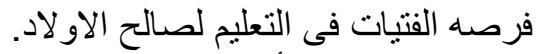
- واوضحت النتائج أن الامهات الغيم الغير متعلمات لا لادئ يحبذن استكمال تعليم الفتيات الى الجامعها، حيث ان الفتاه ستعيش داخل المدينه الجامعيه بمفردها.

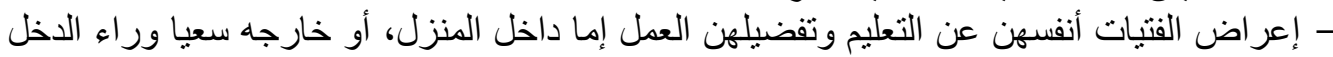

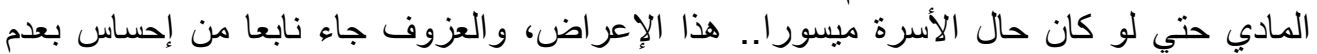

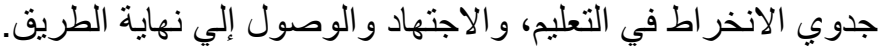

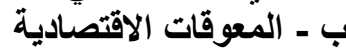

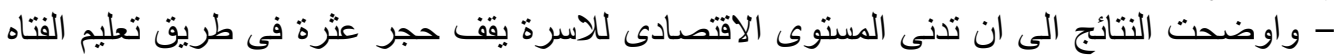

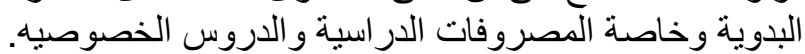

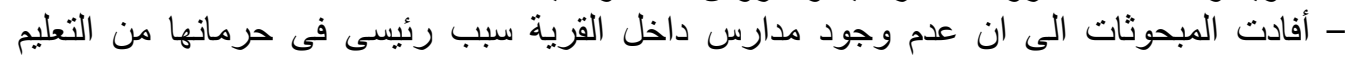

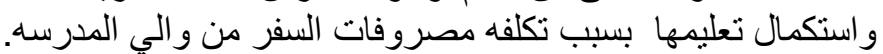
- وأفادت الفتيات ان عملية رعى الغنم تاخذ وفتا كبيراً مما يؤثر على المديه ادائها في تحصيل المواد

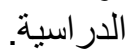
- عدم وجود المدارس الفنيه داخل القرية لايشجع اولياء الامور على ادخال بناتهم فيها بدلا من السفر

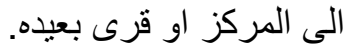

- زياده عدد افر اد الاسره و الاعباء المادية للحياه سبيا فى عدم اقبال الاسره على تعليم الفتاه البدوية. ج - المعوقات الثقافيه - افادت الفتيات ان هنات سلسلة من التراكمات فامت الفات بتغذيتها الموروثات الشعبية التي تسفه دائما من

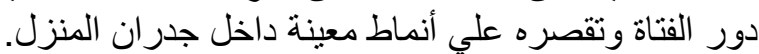

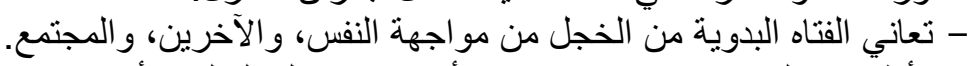

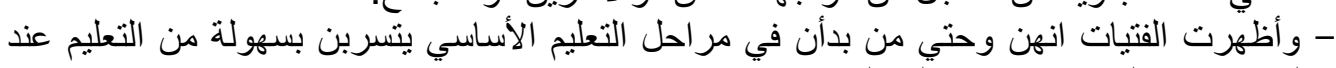

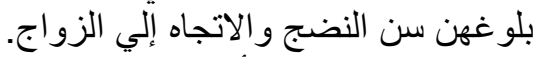

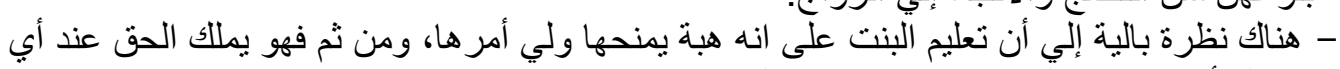

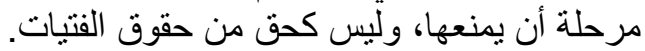
- إن المناهج الدر اسية غير موائمة للبيئة الصحر اوينة

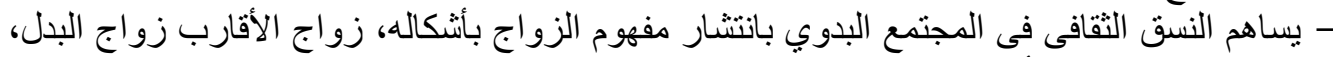

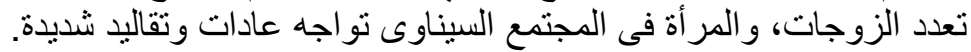

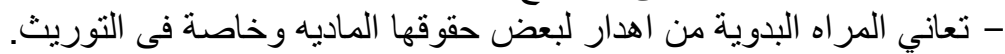

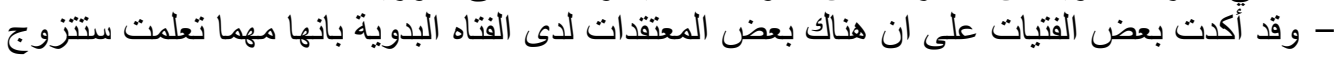
وتربى اطفال فلا داعى لاستكمال التعليه.

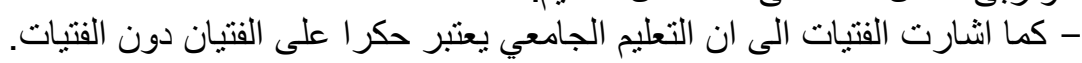

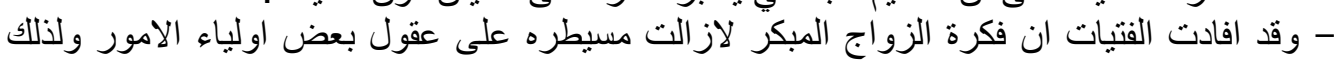
يتم الاكتفاء بمرحله التعليم الاعداديه للفتيات.

Fayoum J. Agric. Res. \& Dev., Vol. 27, No.2, July, 2014 
$\varepsilon r$

- كما اضافت ايضا ان التقاليد البدوية تحول دون خروج البوان الفتاه البدوية و السفر لمسافات بعيده للتعليم. ثانيا : معوقات تعليم الفتاه البدويه من وجهة البدوية نظرل القائمين علي العمليه التعليمية:

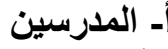

أفادت عينه البحث من المدرسين ومديرى المدارس الذين هم من القائمين على العملية التعليميه

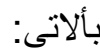
- أن المعلم يعجز عن تقديم ما لديه من معرفة لتلاميذه، بسبب طبيعة الحياة في المناطق النائية، وظروف البدو الاجنماعية.

- تشكل قلة الأعداد المطلوبة من المدرسات والمنة المتخصصات للعمل في مدارس التعليم الإلزامي

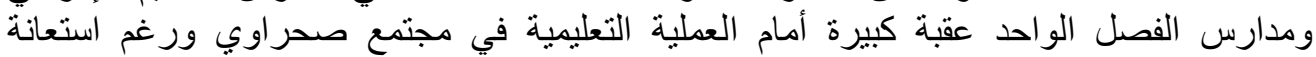

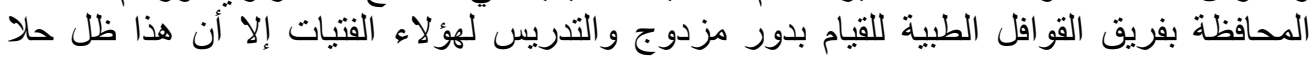

وقتنيا.

- يعزف المعلمون لاسيما الأكفاء منهم عن التعليم في صفوف مجمعة في مناطق نائية، وبيئة قاسية،

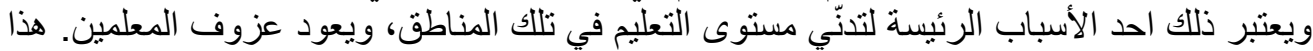

إلى أسباب عديدة منها:

1- بسبب نشأتهم في بيئة حضرية في المدن، وتعوّدهم على الحياة الحئه المريحة فيها، ولهذا فهم يجدون

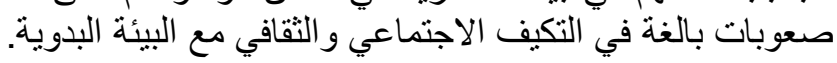

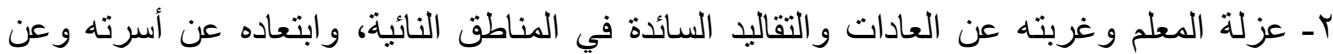

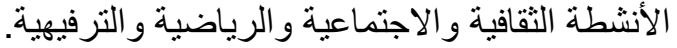

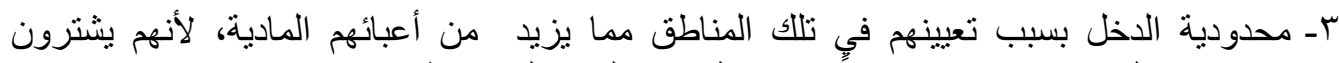
حاجاتهم من المدن، ويصرفون جز عاً من دخولهم في السفر إلى مواطن إلى إقامتهم.

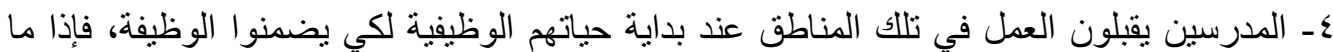

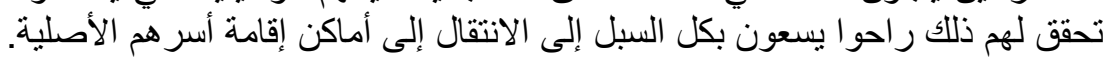

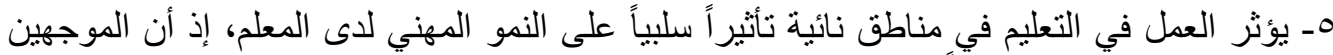

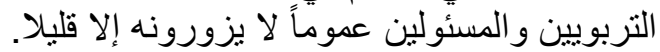

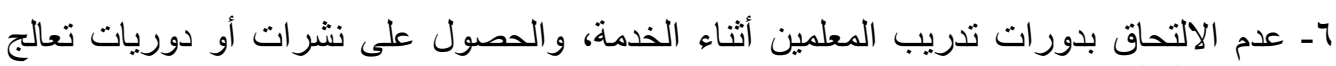
مشكلات التعليم.

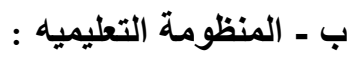

وقد اظهرت النتائج أيضا ان منظومة التعليم فى المناطق الصحر اويه تعاني ضعفا شديدا من حيث:

- - معف الامكانيات المادية. - عدم استقرار الكوادر التعليمية فيها بسبب تطلع كل من يتم تعينه فى تلك المنطقة الى الانتقال في اقرب فرصة الى مناطق حضرية.

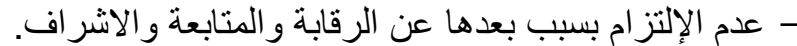

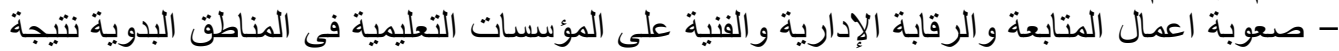

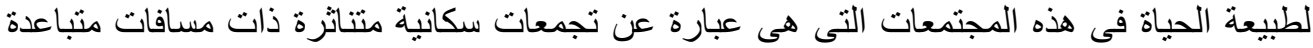

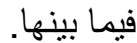

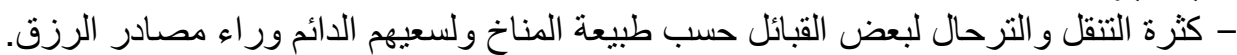

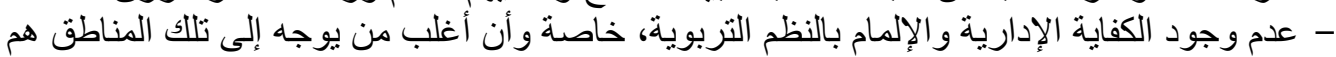

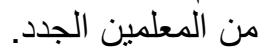

Fayoum J. Agric. Res. \& Dev., Vol. 27, No.2, July, 2014 
$\varepsilon \varepsilon$

- تعاظم المسؤولية، فالمدير هو المسئول عن الطالب و المعلم والمبنى.. و وعلى مدى إخلاصده و إنتاجه

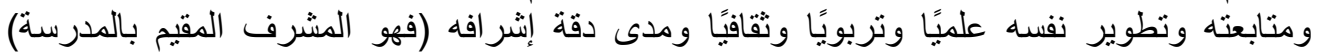

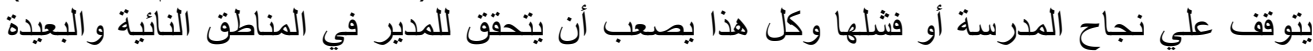
للظروف البيئية وحالته النفسية.

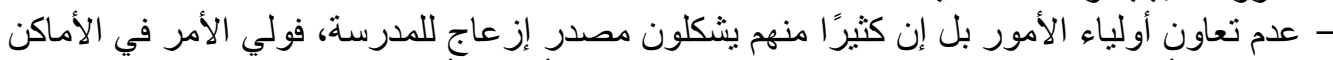

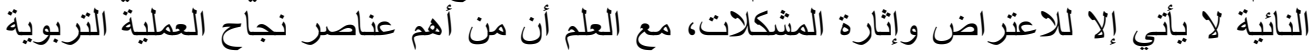

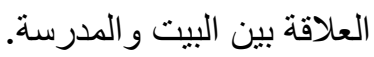

- عدم تعاون المعلمين في تسيير عمل المدرسة لقلة الخبرة و عدم الإحساس بالمسؤولية.

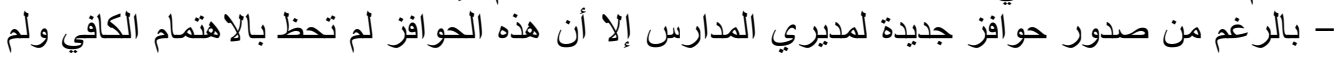

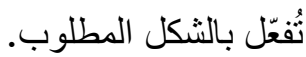
- كثرة الأعمال الإدارية، فالواجبات الإدارية عديدة ومتتوعة مما يتطلب الكثير من الوقت والجهد بجانب الأعمال الإشر افية والتقويمية، مع عدم وجود كادر إداري أو كتابي في المدارس النائية. - بُعد المدارس وصعوبة التنقل منها و إليها وظروف الحياة القاسية في تلك المناطق. - مقارنة مدير المدرسة وجميع المعلمين أنفسهم بزملانئهم في المدن و المحافظات الأخرى.

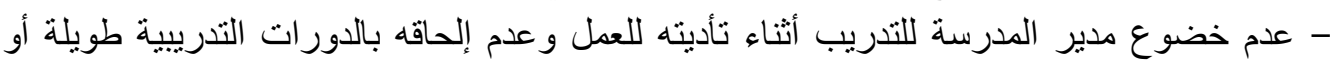

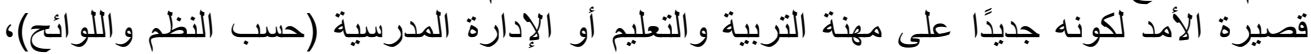
ولبعد المسافات ووعورة الطرق التي تكون عائقًا أمام حضوره حتى للأساليب الإشر افية. - مشكلات الطلاب وبعض السلوكيات الخاطئة التي وصلت إلى حد العنف ضد المعلمين وإدارة المدرسة.

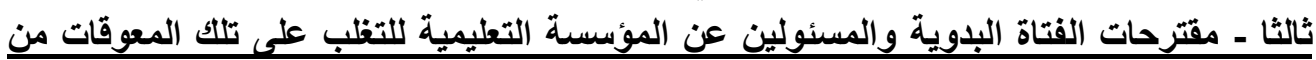

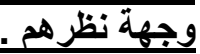

أ- مقترحات الفتاه البدوية : أفادةت الفتيات اثتاء المناقثات بالاتي:

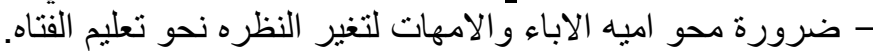

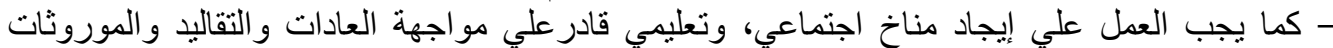
السلبية التي تحد من تعليم الفتيات مثل: رفض اختلاطيهن بزملاتلائهن من الذكور في التعليم واستنفاد

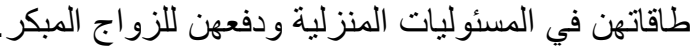
- انتظام تو اجد المدرسين داخل المدارس لموسئة الصنلة العملية التعليمية.

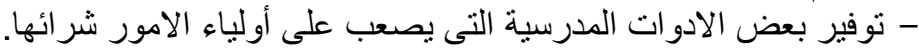

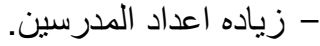

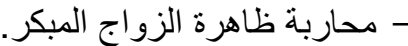
- توفير المدارس داخل القرى حتى تنتمكن الفتاه من استكمال تعليمها مثل المدارس الثانويه و الثانثانوية الفنيه.

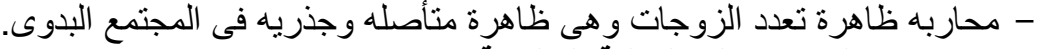

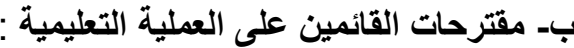

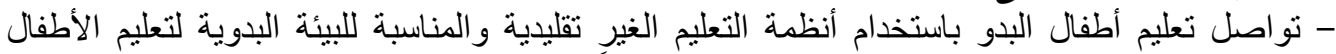
القر اعة و الكتابة والحساب ومبادئ الدين، ومن المفيد جداً إدخال مناهج المدرسة الابتدائية المناسبة للبيئة وفي صلب عمل تللك المؤسسات التعليمبة. - جعل التعليم الاساسي وفق مناهج الدولة المركزية مع مرونة في التطبيق وزيادة الاعتماد على التعلم النشط، ولكي تضمن الفاعلية و الكفاية.

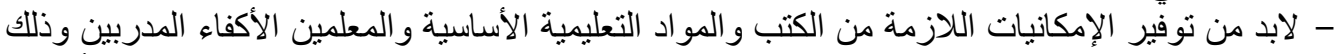
بهدف جعل فرص التعلم لاى فنيات البدو مكافئة مع فرص الأن التعليم لجميع الفتيات في سن التعليم الأساسي

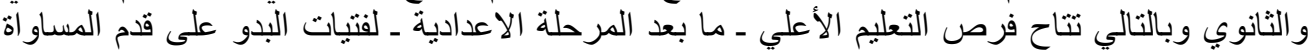
مع الفتيات المستقرين من جهة وسد منابع أمية الكبار من جهة الخئ أخرى.

Fayoum J. Agric. Res. \& Dev., Vol. 27, No.2, July, 2014 
- تفعيل المدارس المتتقلة التى يمكن لها الوصول الى المناطق التى يصعب الوصول اليها او اقامة منشآت هدآ

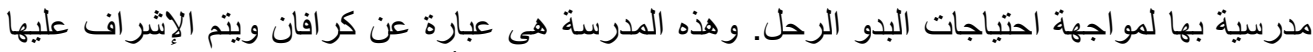

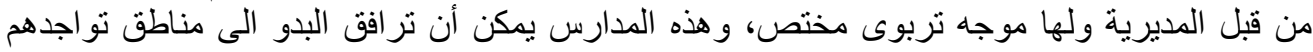
واستقر ار هم فى اماكن بعيدة. - التركيز إلى أقصى حد مدكن على امكيد انتقاء المعلمين ويفضل أبناء البيئة نفسها، لأن هذا بكفل تكيف المعلم

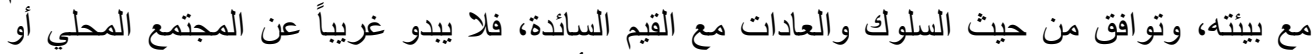

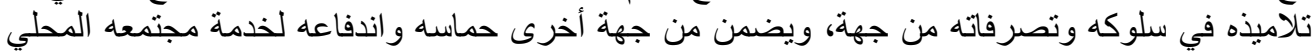

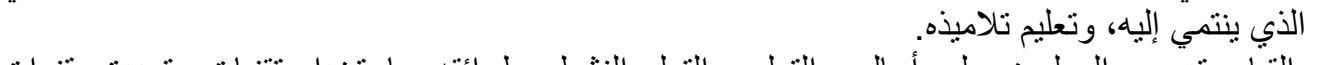
- القيام بتدريب المعلمين على أساليب التعليم و التعلم النشط وطر ائقه، باستخدام تقنيات متعددة وقنوات

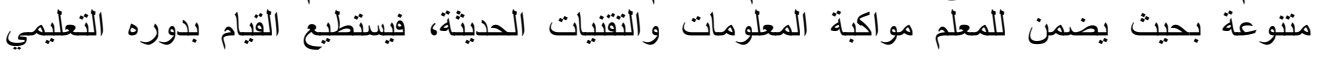
والإرشادي في المدرسة والقيادي في المجتمع المحلي.

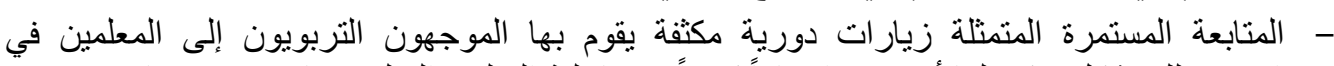

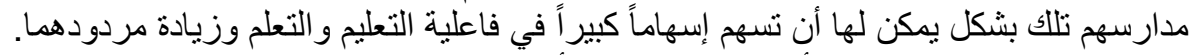

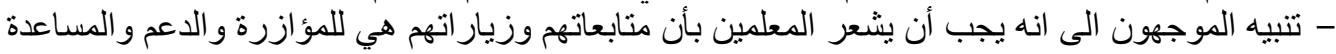

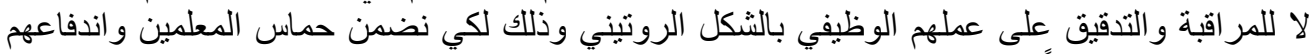

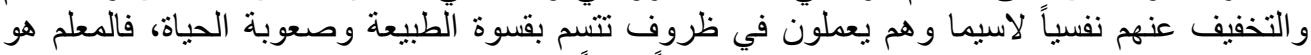

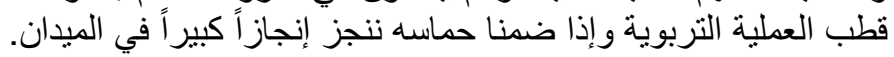

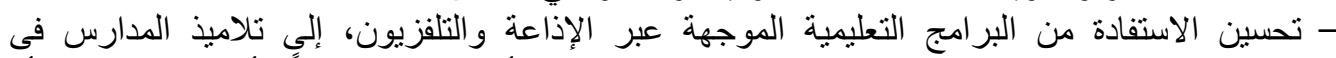

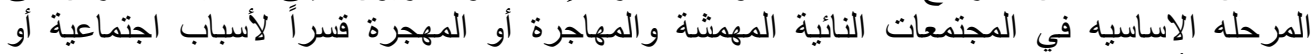
اقتصادية أو طارئه والاستفادة من المساعدات التي تقدمها المنظمات الدولية والإقليمية المعنية بالتعليم

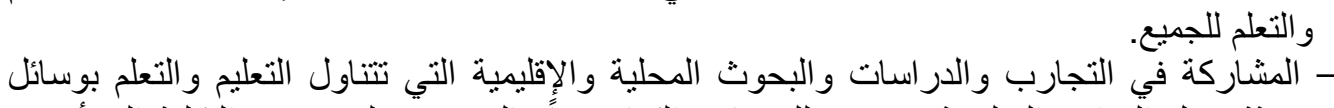

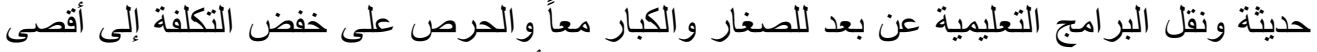

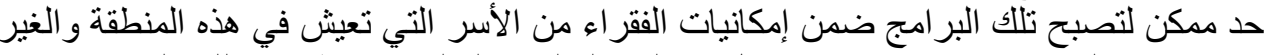
-مستقرة ثم القيام بدراسات ميدانية حول فاعلية التعليم والتعلم عن طريق تللك البرامج وتعديلها

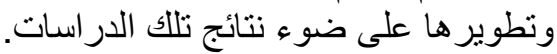
- الاهتمام باستمرار التركيز على تعلى تعليم الأسس والمبادئ والقوانئ النين العلمية في العلوم الإنسانية و الطبيعية، وإبراز تطبيقاتها الو اقعية في البيئة المحلية. - الحرص على جعل المدرسة الابتدائية كمرحله اولي جذابة للتلاميذ وأولية ألياء الأمور، ففي مجال العملية التربوية يجب على المعلمين استخدام طر ائق التدريس الحديثة الجذابة ومعاملة التلاميذ في

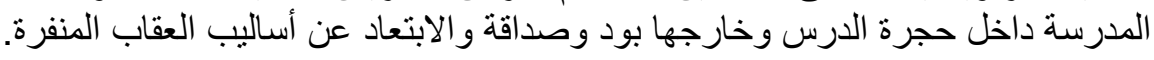
- التعليق على النتائج:

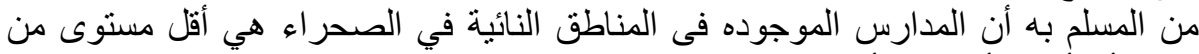

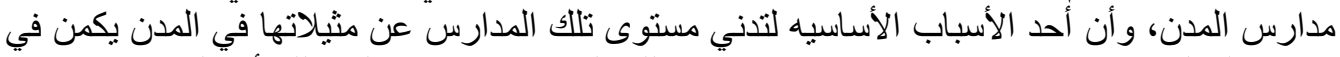

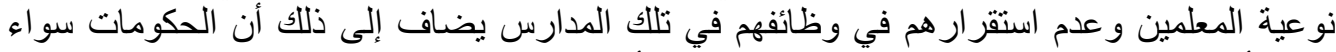

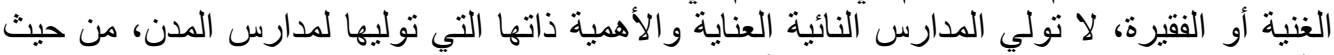

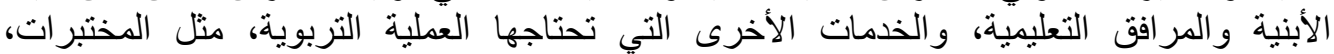
و الملاعب و المكتبات و غير ها. التوصيات:

ولذلك ومن خلال الحوار بين الباحثين و المبحوثين من الفتيات و المسئولين عن العمليه

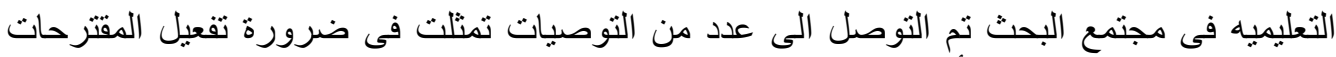

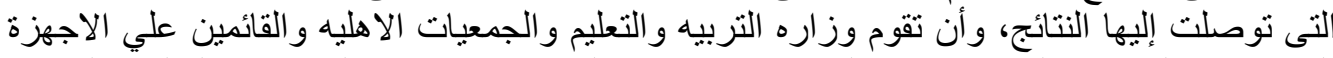

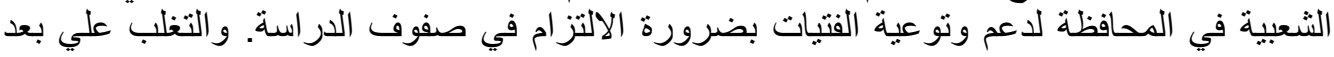

Fayoum J. Agric. Res. \& Dev., Vol. 27, No.2, July, 2014 


\section{$\varepsilon 7$}

التجمعات البدوية عن الفصول الدراسية بفتح فصول دراسية داخل المنازل او تفعيل المدارس المتنقلة

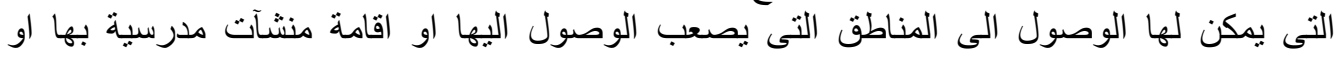

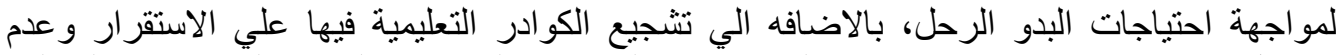

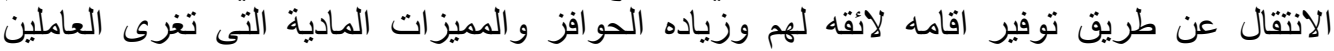

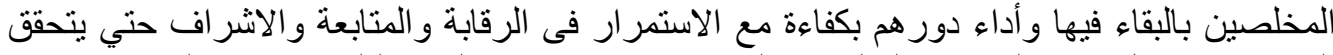

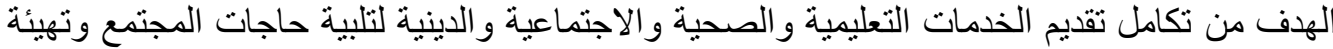
الفرص الأفضل للتعليم والتعلم.

Fayoum J. Agric. Res. \& Dev., Vol. 27, No.2, July, 2014 


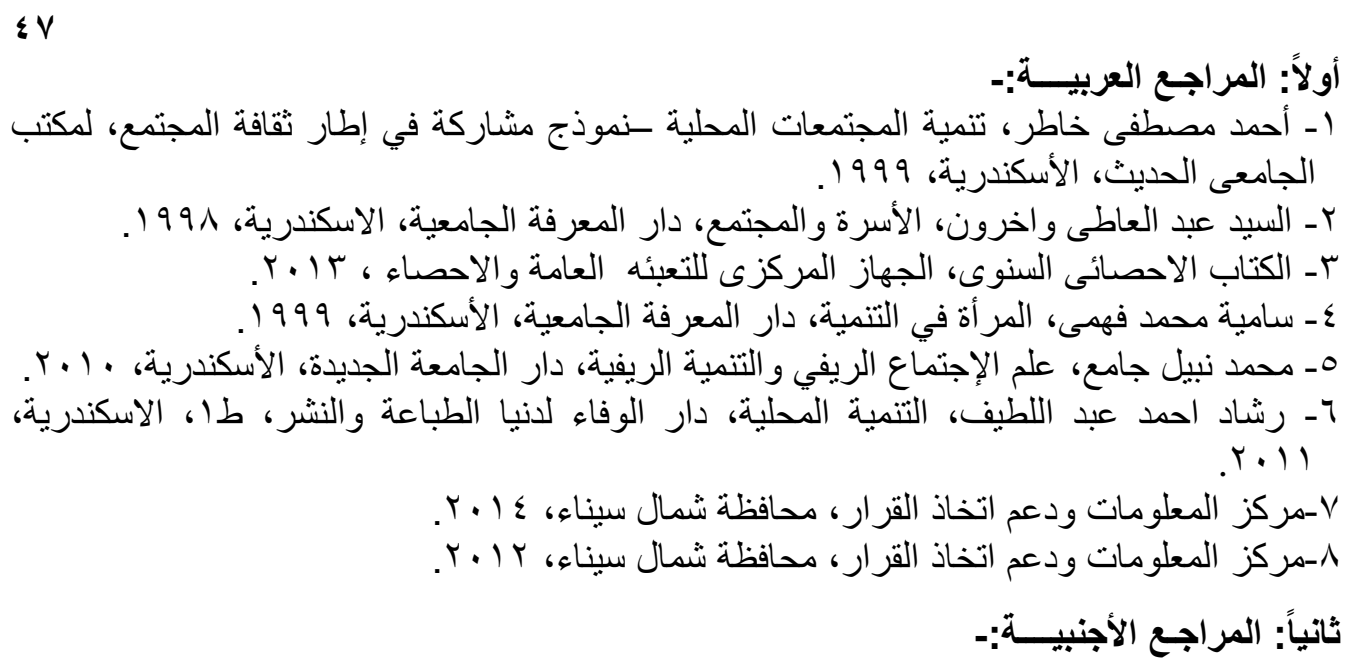

1- Ministry of education "Education in Egypt" national center for education research center, 1980.

2- F.M.loewen Bery fundamentals of social intervention ,new york, Guild fed , 1983.

\title{
OBSTACLES TO BEDOUIN GIRLS' EDUCATION IN NORTH SINAI GOVERNORATE
}

\section{DR. Ashoura hussien Mohamed Morsy And DR.Ahmed Anwar Refae Desert Research Center -Cairo}

\begin{abstract}
:
The research targeted to identify the most important social, cultural and economic constraints that impede the Bedouin girls' education. And also the most important obstacles from the perspective of those responsible for the educational process, and then identify the most important Bedouin girl's proposals and those responsible for the educational institution to overcome those obstacles from their point of view.

we selected 40 girls Bedouin from the once attending schools, ( preparatory, high or universities, and the sample were simple random selected from prep and sec, school lists by school staff but female students in universities were selected by a local leaders of the selected villages, also of officials from the educational process (teachers, and administrators of schools), were involved in the selections, the selection process reached 30 per person.

It was the work of an interview guide includes two main pillars: social and cultural obstacles that hinder the Bedouin girls' education from the point of view of the Bedouin girl and responsible for the educational process and respondents proposals to resolve these obstacles in the research area and used in the data collection method of this research focus group discussion and build on it included seven research groups, in-depth discussion by ten respondents in each group, data were collected during the month (September) 2014.
\end{abstract}

Fayoum J. Agric. Res. \& Dev., Vol. 27, No.2, July, 2014 
$\varepsilon \wedge$

\section{The main search results as follows:}

The results showed that the most important social obstacles expressed by the girls is the distance from home to school (3-5) $\mathrm{km}$, and there is a severe case of reluctance among the Bedouin to education girls and that because the desire of their parents to marry them once the girl reach the adulthood and showing femininity landmarks Some prefer her stay in the house.

The most important cultural obstacles that there are a series of accumulations have fed popular traditions which always reduce the role of the girl and shortened to certain patterns inside the walls of the house. In addition to what the Bedouin girl suffers from the shame of face herself, the others, and the community.

Girls also showed that even when they have begun in the stages of basic education; we find that they easily drop out of education at the age of maturity and going to marriage.... And that there is outdated view emphasizes that who gives the girl the gift of education her guardian, and then he has the right at any stage to prevent it, and not as a right of the rights of girls.

The results also showed that the most important economic obstacles for Bedouin girls' education is the low economic level of the family, who stands a stumbling block in the way of Bedouin girls' education and private tuition fees and tutoring, and increase the number of family members and material burdens of life are the reason of the lack of blockbuster the family on girls' education.

One of the most important obstacles from the point of view based on the educational process follows:

That the teacher is unable to provide his knowledge to his disciples, also incapable of give his experience to their advantage, because of the nature of life in remote areas, and conditions of Bedouin social, and because of growing up in an urban environment in the cities, and their familiarity with the comfortable in life, and that they find great difficulties in adapting social and cultural environments with the Bedouins and the limited income because of their hired them in those areas which is increases the material burdens...

The most important proposals are the literacy of parents to change their view towards girls' education, and must work to find a social and educational climate able to face the customs and traditions and the negative legacies that limit girls' education, such as:

* Exhausted their energies in household responsibilities and forcing them to early marriage...

* Regularity of the presence of teachers in the schools to continue the educational process.

* Providing some school supplies that are difficult for parents to buy them.

* Increase the number of teachers.

* Combat the phenomenon of early marriage.

* The provision of schools in the villages so that the girl can complete her education, such as high schools and technical secondary school.

* Combat the phenomenon of polygamy, which is inherent and rooted phenomenon in the Bedouin community.

Fayoum J. Agric. Res. \& Dev., Vol. 27, No.2, July, 2014 